\title{
CARBOHYDRATE METABOLISM IN INTACT SKELETAL MUSCLE IN MAN DURING THE NIGHT ${ }^{1}$
}

\author{
BY KENNETH L. ZIERLER AND REUBIN ANDRES
}

\author{
(From the Departments of Environmental Medicine and Medicine, The Johns Hopkins Uni- \\ versity and Hospital, Baltimore, Md.)
}

(Submitted for publication March 20, 1956; accepted May 17, 1956)

It is customary in many metabolic studies to reduce variables by limiting observations to the socalled basal state in which the subject is not only at rest but also has been fasted for 14 hours or more. Despite the usefulness of this standardization it must be remembered that the basal state is unique; for example, during man's waking hours no more than four to six hours elapse between meals.

In a previous study (1) it was shown that in normal man in the basal state resting skeletal muscle (exemplified by forearm tissues) oxidizes noncarbohydrate substrates, in the main, and despite vigorous oxygen consumption, produces lactate. Since these results ran counter to concepts held generally it was conceivable that they were characteristic only of early starvation since they were obtained between the hours of 10 A.M. and noon, that is, 16 to 18 hours after the last meal. To examine this possibility observations of forearm metabolism in three normal men have been made throughout the night, beginning four to six hours after the evening meal and continuing through the period defined previously as the basal state. Measurements were made of $\mathrm{O}_{2}$ and glucose uptake and $\mathrm{CO}_{2}$ and lactate production by application of the Fick principle, $\dot{Q}=F(A-V)$, where $\dot{Q}$ is rate of uptake or production, $F$ is blood flow, and $\mathrm{A}$ and $\mathrm{V}$ are concentrations in arterial and in venous blood, respectively.

\section{METHODS}

Normal subjects were three fourth-year medical students in good health. They ate their usual evening meal at about 6 P.M. and reported to the laboratory between three and four hours later. They were immediately put

\footnotetext{
1 This work was performed under a contract between the Office of Naval Research, Department of the Navy, and The Johns Hopkins University (NR 113-241), and was further supported by grants-in-aid from the National Institutes of Health, Department of Health, Education and Welfare (H-1327, A-750) and the Muscular Dystrophy Associations of America, Inc.
}

to bed and made as comfortable as possible. An 18-gauge Riley needle was inserted in a brachial artery and a deep and a superficial antecubital vein were catheterized as described previously (2). Intravenous catheters were kept patent between sampling periods by slow infusion of $155 \mathrm{mM} \mathrm{NaCl}$ solution at a rate of approximately $20 \mathrm{ml}$. per hr. Eight or nine pairs of arterial and venous samples were collected through the night and during the following morning. During this time the subjects had neither food nor drink. Two of them fell asleep shortly after the procedure started and had to be awakened in the morning. The third, subject $\mathrm{N}$, slept only fitfully and complained so bitterly of pain in his arm that he had to be given codeine, $32 \mathrm{mg}$., at 3 A.M. and again at 3:50 A.M. At least five minutes before each collection period a sphygmomanometer cuff about the wrist was pumped to at least $200 \mathrm{~mm} . \mathrm{Hg}$ pressure to exclude the hand from the forearm circulation and intra-arterial injection of T-1824 at constant rate was instituted to give a measure of blood flow as described previously (2). The cuff was released and the injection discontinued immediately after collection of each pair of blood samples. Each blood sample was $18 \mathrm{ml}$. in volume, collected in $20-\mathrm{ml}$. syringes, the dead space of which was filled with heparin. Handling of blood and analytical methods were as previously described $(1,2)$. Venous concentration of metabolites was determined only in blood from the deep vein draining muscle. To discover whether or not venous blood was diluted by backflow of the infused $\mathrm{NaCl}$ solution hematocrits were determined on each sample. No such contamination was detected.

\section{RESULTS}

Results appear in Table I A, B and C and in Table II.

\section{Blood flow}

There was no evidence of diurnal variation in blood flow. Although there is no way of knowing whether or not there were rapid changes of great magnitude in flow at times not sampled, if these were absent, the changes in flow as measured occurred over an hour or two and the change in flow per minute was probably too small to jeopardize the validity of application of the Fick principle which, of course, depends upon the existence 
TABLE I

Blood flow and metabolism of the forearm during the night*

\begin{tabular}{|c|c|c|c|c|c|c|c|c|c|c|c|c|c|}
\hline \multirow[b]{2}{*}{ Time } & \multirow{2}{*}{$\begin{array}{l}\text { Blood } \\
\text { flow }\end{array}$} & \multicolumn{3}{|c|}{ Oxygen } & \multicolumn{3}{|c|}{$\mathrm{CO}_{2}$} & \multicolumn{3}{|c|}{ Glucose } & \multicolumn{3}{|c|}{ Lactate } \\
\hline & & A & $(A-V)$ & $\dot{\mathrm{Q}}$ & A & $(A-V)$ & $\dot{Q}$ & A & $(A-V)$ & $\dot{\mathbf{Q}}$ & $\mathbf{A}$ & $(A-V)$ & $\dot{Q}$ \\
\hline \multicolumn{14}{|c|}{ A. Subject $C$} \\
\hline $\begin{array}{l}11: 47 \text { P.M. } \\
1: 03 \text { A.M. } \\
2: 03 \\
3: 03 \\
5: 03 \\
7: 03 \\
9: 03 \\
10: 03 \\
11: 03\end{array}$ & $\begin{array}{l}4.35 \\
4.13 \\
5.15 \\
4.41 \\
6.92 \\
3.23 \\
3.94 \\
6.30 \\
3.23\end{array}$ & $\begin{array}{l}8.27 \\
8.31 \\
8.21 \\
7.95\end{array}$ & $\begin{array}{l}3.48 \\
4.20 \\
3.70 \\
4.15\end{array}$ & $\begin{array}{l}15.4 \\
29.1 \\
11.9 \\
16.3\end{array}$ & $\begin{array}{l}21.64 \\
21.07 \\
21.27 \\
21.10\end{array}$ & $\begin{array}{l}-2.92 \\
-3.51 \\
-3.11 \\
-3.56\end{array}$ & $\begin{array}{l}12.9 \\
24.3 \\
10.0 \\
14.0\end{array}$ & $\begin{array}{l}5.00 \\
5.20 \\
5.11 \\
5.01 \\
4.82 \\
4.74 \\
4.74 \\
4.73 \\
4.67\end{array}$ & $\begin{array}{r}0.30 \\
0.25 \\
0.16 \\
0.01 \\
0.13 \\
0.01 \\
0.07 \\
0.01 \\
-0.09\end{array}$ & $\begin{array}{r}1.30 \\
1.03 \\
0.82 \\
0.04 \\
0.90 \\
0.03 \\
0.28 \\
0.06 \\
-0.29\end{array}$ & $\begin{array}{l}0.452 \\
0.442 \\
0.405 \\
0.463 \\
0.464 \\
0.447 \\
0.493 \\
0.479 \\
0.509\end{array}$ & $\begin{array}{l}-0.072 \\
-0.109 \\
-0.114 \\
-0.068 \\
-0.075 \\
-0.101 \\
-0.104 \\
-0.154 \\
-0.119\end{array}$ & $\begin{array}{l}-0.313 \\
-0.450 \\
-0.587 \\
-0.300 \\
-0.519 \\
-0.326 \\
-0.410 \\
-0.970 \\
-0.384\end{array}$ \\
\hline \multicolumn{14}{|c|}{ B. Subject $K$} \\
\hline \multirow[t]{2}{*}{$\begin{array}{r}11: 56 \text { P.M. } \\
1: 05 \text { A.M. } \\
2: 00 \\
3: 33 \\
5: 03 \\
6: 34 \\
8: 04 \\
10: 16 \\
10: 37 \\
11: 04\end{array}$} & \multirow[t]{3}{*}{$\begin{array}{l}3.34 \\
3.53 \\
3.00 \\
3.39 \\
2.84 \\
2.36 \\
3.09 \\
3.62 \\
3.20 \\
3.37\end{array}$} & $\begin{array}{l}9.79 \\
9.58 \\
9.60 \\
9.44 \\
9.51 \\
9.49 \\
9.45 \\
9.71 \\
9.84 \\
9.69\end{array}$ & $\begin{array}{l}3.07 \\
\\
2.53 \\
2.50 \\
2.37 \\
3.06 \\
2.66 \\
2.36 \\
2.84 \\
2.04\end{array}$ & $\begin{array}{l}7.59 \\
8.48 \\
6.73 \\
7.22 \\
8.22 \\
8.54 \\
9.09 \\
6.87\end{array}$ & $\begin{array}{l}21.58 \\
21.62 \\
21.82 \\
21.23 \\
21.72 \\
22.18 \\
22.23 \\
22.20 \\
22.34 \\
21.90\end{array}$ & $\begin{array}{l}-2.16 \\
-2.04 \\
-2.55 \\
-1.83 \\
-2.53 \\
-2.86 \\
-2.19 \\
-2.14 \\
-2.31\end{array}$ & $\begin{array}{l}7.21 \\
\\
6.12 \\
8.64 \\
5.20 \\
5.97 \\
8.84 \\
7.93 \\
6.85 \\
7.78\end{array}$ & $\begin{array}{l}4.99 \\
4.87 \\
4.79 \\
5.02 \\
4.67 \\
4.91 \\
4.79 \\
4.70 \\
4.80 \\
4.95\end{array}$ & $\begin{array}{r}0.05 \\
0.17 \\
0.52 \\
0.14 \\
0.48 \\
0.20 \\
-0.19 \\
-0.02 \\
0.09\end{array}$ & $\begin{array}{r}0.51 \\
1.76 \\
0.40 \\
1.13 \\
0.62 \\
-0.69 \\
-0.06 \\
0.30\end{array}$ & $\begin{array}{l}0.610 \\
0.486 \\
0.533 \\
0.583 \\
0.562 \\
0.598 \\
0.597 \\
0.563 \\
0.565 \\
0.543\end{array}$ & $\begin{array}{l}-0.128 \\
-0.176 \\
-0.169 \\
-0.256 \\
-0.328 \\
-0.318 \\
-0.281 \\
-0.259 \\
-0.272\end{array}$ & $\begin{array}{l}-0.428 \\
-0.528 \\
-0.573 \\
-0.727 \\
-0.774 \\
-0.983 \\
-1.017 \\
-0.829 \\
-0.917\end{array}$ \\
\hline & & \multicolumn{3}{|c|}{ Oxygen } & \multicolumn{3}{|c|}{$\mathrm{CO}_{2}$} & & \multicolumn{2}{|c|}{ Glucose } & \multicolumn{3}{|c|}{ Lactate } \\
\hline Time & & $\mathbf{A}$ & (A-V & & A & & A-V) & & A & $(\mathrm{A}-\mathrm{V})$ & & A & $(\mathrm{A}-\mathrm{V})$ \\
\hline \multicolumn{14}{|c|}{ C. Subject $N$} \\
\hline $\begin{array}{c}10: 08 \text { P.M. } \\
11: 35 \\
1: 04 \text { A.M. } \\
3: 04 \\
5: 08 \\
7: 07 \\
8: 04 \\
9: 09\end{array}$ & & $\begin{array}{l}9.16 \\
9.04 \\
8.82 \\
9.03 \\
8.86 \\
8.87 \\
8.91 \\
9.09\end{array}$ & $\begin{array}{l}2.0 \\
2.0 \\
2.5 \\
2.2 \\
2.2 \\
2.0 \\
2.2 \\
2.6\end{array}$ & & $\begin{array}{l}21.70 \\
20.93 \\
21.13 \\
20.86 \\
21.44 \\
20.86 \\
20.85 \\
21.00\end{array}$ & & $\begin{array}{l}-1.98 \\
-1.91 \\
-2.01 \\
-1.53 \\
-1.09 \\
-1.67 \\
-1.65 \\
-1.56\end{array}$ & & $\begin{array}{l}5.32 \\
5.53 \\
5.28 \\
4.89 \\
4.52 \\
4.67 \\
4.86 \\
4.80\end{array}$ & $\begin{array}{r}0.56 \\
0.30 \\
0.50 \\
-0.10 \\
-0.19 \\
0.19 \\
0.30 \\
0.25\end{array}$ & & $\begin{array}{l}0.583 \\
0.663 \\
0.601 \\
0.672 \\
0.604 \\
0.651 \\
0.595 \\
0.611\end{array}$ & $\begin{array}{l}-0.295 \\
-0.113 \\
-0.084 \\
+0.098 \\
-0.028 \\
-0.125 \\
-0.246 \\
-0.090\end{array}$ \\
\hline
\end{tabular}

* Time refers to time at which arterial blood was sampled.

Units: Blood flow, $\mathrm{ml} . / \mathrm{min} . / 100 \mathrm{ml}$. forearm; $\mathrm{A}=$ arterial concentration, $\mathrm{mM} /$ liter whole blood; $(\mathrm{A}-\mathrm{V})=$ arterialvenous concentration difference, $\mathrm{mM} / \mathrm{liter} ; Q=$ uptake or outflow, $\mu \mathrm{M} / \mathrm{min}$. $/ 100 \mathrm{ml}$. forearm. All values for $Q_{\mathrm{CO}_{2}}$ are negative.

of a steady state. In subject $\mathrm{N}$ it was possible to sample only from the deep vein. Since the method for measuring blood flow cannot be validated unless mixing of T-1824 and blood is demonstrated by analysis of blood from two veins, no data for blood flow are reported for this subject.

\section{$\mathrm{O}_{2}$ uptake}

Oxygen uptake, although quite variable, did not change systematically with time. In general, A-V differences in $\mathrm{O}_{2}$ content were more constant than $\mathrm{O}_{2}$ uptake. In one subject $\mathrm{O}_{2}$ uptake varied linearly with blood flow; in the other, neither flow nor $\mathrm{O}_{2}$ uptake varied sufficiently to make it appropriate to test for correlation.

\section{$\mathrm{CO}_{2}$ production}

There was no temporal trend in $\mathrm{CO}_{2}$ production. Arterial $\mathrm{CO}_{2}$ concentrations were quite constant.

\section{Glucose uptake}

Arterial glucose concentration decreased with time (Figure 1). Although in one subject, $K$, no clear-cut trend is evident, the association of decreasing arterial concentration with increasing time is excellent when the whole body of data is tested $(P<0.01)$. There was a similar trend toward decreasing $\mathrm{A}-\mathrm{V}$ differences in glucose concentration and toward decreasing glucose uptake. Indeed a high correlation $(p<0.01)$ exists 
TABLE II

Per cent of glucose uptake accounted for by lactate production and per cent of $\mathrm{O}_{2}$ uptake accounted for by glucose oxidation

\begin{tabular}{|c|c|c|c|c|c|c|}
\hline \multirow[b]{2}{*}{ Period* } & \multicolumn{3}{|c|}{ L/G† } & \multicolumn{3}{|c|}{$(\mathrm{G}-\mathrm{L}) / \mathrm{O}_{2} \ddagger$} \\
\hline & Subj. & Subj. & Subj. & Subj. & $\underset{\mathbf{K}}{\text { Subj. }}$ & Subj. \\
\hline II & $\begin{array}{r}25 \\
66 \\
\text { All }\end{array}$ & $\begin{array}{r}32 \\
56 \\
\text { All }\end{array}$ & $\begin{array}{l}15 \\
44\end{array}$ & $\begin{array}{r}17 \\
3 \\
-18\end{array}$ & $\begin{array}{r}40 \\
25 \\
-44\end{array}$ & $\begin{array}{l}78 \\
21\end{array}$ \\
\hline
\end{tabular}

* Period I, approximately 10 P.M.-4 A.M.; Period II, approximately 4-10 A.M.; Period III, after 10 A.M.

† $\mathrm{L} / \mathrm{G}=$ per cent of glucose uptake accounted for by lactate production.

$\ddagger(\mathrm{G}-\mathrm{L}) / \mathrm{O}_{2}=$ per cent of $\mathrm{O}_{2}$ uptake accounted for by apparent oxidation of glucose.

between arterial glucose concentration and A-V differences (Figure 2). The range of arterial glucose concentrations was 4.5 to $5.5 \mathrm{mM}$ per L. or 81 to $100 \mathrm{mg}$. per $100 \mathrm{ml}$. of blood.

Spurious correlation between arterial glucose concentration and A-V difference would occur in the presence of technical error. A falsely high value for arterial glucose concentration would yield a falsely high A-V difference. Similarly, a falsely low value for venous glucose concentrate would yield a falsely high A-V difference. However, there was no correlation between venous glucose concentration and A-V difference. Since there is no reason to suspect that errors in estimate of arterial glucose were larger than those in estimate of venous glucose, it is likely that the correlation found between arterial glucose and A-V difference is not an artefact. Furthermore, even when the data are challenged by assuming

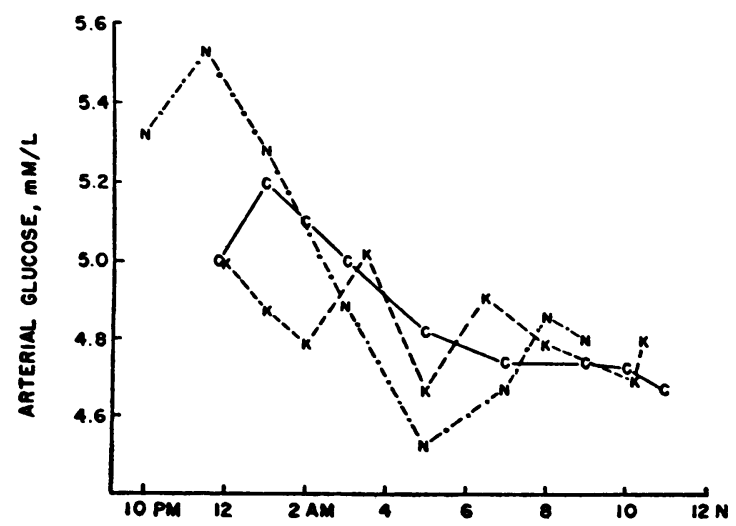

Fig. 1. Decrease in Arterial Glucose Concentration WiTh TIME

$\mathrm{C}, \mathrm{K}$, and $\mathrm{N}$ each represent a subject.



Fig. 2. Correlation Between Arterio-Venous DifFerence and Arterial Glucose Concentration

$\mathrm{C}, \mathrm{K}$, and $\mathrm{N}$ each represent a subject.

errors of two standard deviations in measurements of arterial glucose concentrations the correlation between arterial glucose and $\mathrm{A}-\mathrm{V}$ difference is upheld.

\section{Lactate production}

Lactate was produced by resting forearm throughout the night. There was no temporal trend in lactate production. Arterial lactate concentration remained constant.

Fraction of glucose uptake accounted for by lactate production: $L / G$

The expression $1 / 2$ (V-A lactate difference)/ (A-V glucose difference) yields the fraction of glucose uptake accounted for by lactate production when concentrations are expressed in moles. This value increased during the night (Figure 3 ) until in Period III all the glucose uptake was accounted for by lactate production either owing to negative $\mathrm{A}-\mathrm{V}$ glucose differences (three observations) or to very small $\mathrm{A}-\mathrm{V}$ glucose differences in the presence of particularly large V-A lactate differences (two observations).

\section{Fraction of $\mathrm{O}_{2}$ uptake accounted for by oxidation of glucose: $(G-L) / \mathrm{O}_{2}$}

As described previously (1), when lactate production is subtracted from glucose uptake and the remaining glucose is assumed to have been oxidized an estimate can be made of the fraction of $\mathrm{O}_{2}$ uptake accounted for by oxidation of glucose. 


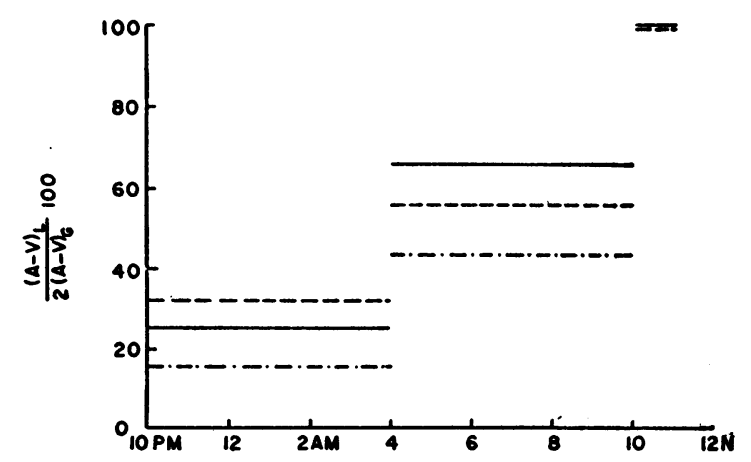

Fig. 3. Increase with Time of the fraction of Glucose Uptake Accounted for by Lactate Production

Solid line, subject $C$; dashed line, $K$; dash-dot line, $N$. Data represent mean values for each of three experimental periods: Period I, 10 P.M.-4 A.M.; Period II, 4 A.M.-10 A.M.; Period III, after 10 A.M., corresponding to time during which basal state observations were made previously (1).

As shown in Figure 4, this fraction decreases throughout the night.

The fraction of $\mathrm{O}_{2}$ uptake accounted for by oxidation of glucose is determined by the expression $6\left[(\mathrm{~A}-\mathrm{V})_{\mathrm{G}}-1 / 2(\mathrm{~V}-\mathrm{A})_{\mathrm{L}}\right] /(\mathrm{A}-\mathrm{V})_{\mathbf{O}_{2}}$, where subscripts refer to concentrations of glucose, lactate and oxygen, respectively. The value depends upon three A-V differences. When the fraction (G-L)/ $\mathrm{O}_{2}$ was plotted against each of these three A-V differences, in turn, it was clear that variations in the fraction were independent of $\mathrm{A}-\mathrm{V}$ differences for lactate and for $\mathrm{O}_{2}$ but were quite dependent

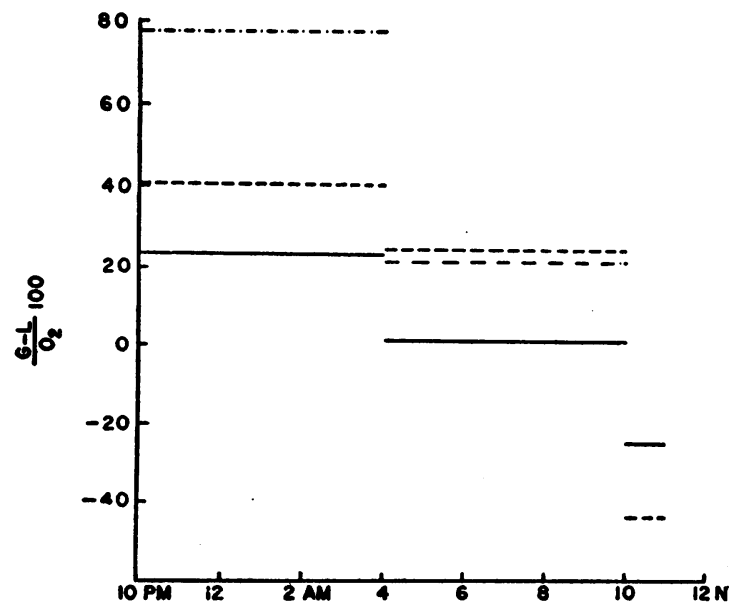

Fig. 4. Decrease with Time of the Fraction of Forrarm $\mathrm{O}_{2}$ Uptake Accounted for by Oxidation of GLucose

See legend to Figure 3.

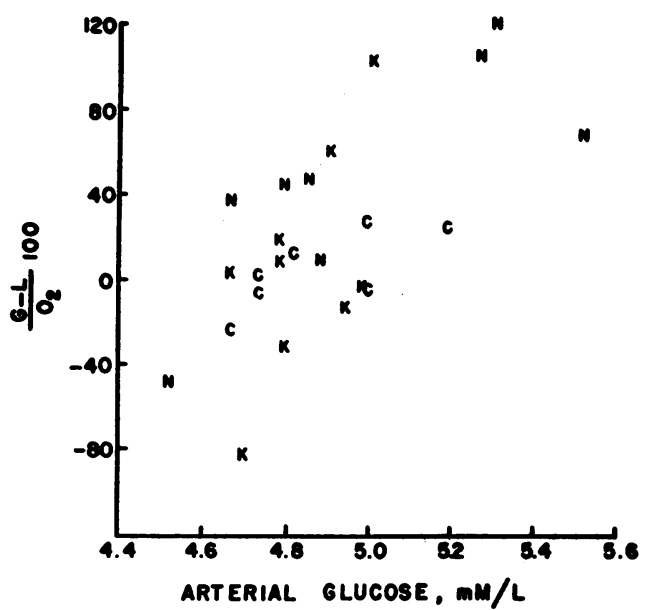

Fig. 5. Correlation between (G-L)/O $/ 2$ and Arterial Glucose Concentration

$\mathrm{C}, \mathrm{K}$, and $\mathrm{N}$ each represent a subject.

upon variations in glucose $\mathrm{A}-\mathrm{V}$ difference. Since glucose $\mathrm{A}-\mathrm{V}$ difference correlated with arterial glucose concentration, it is not surprising that (G-L) $/ \mathrm{O}_{2}$ also varies with arterial glucose concentration (Figure 5). Barring the possibility, noted above and considered unlikely, that the correlation between glucose A-V difference and arterial glucose concentration is an artefact, it would appear that the higher the concentration of glucose in arterial blood, the higher the rate of glucose uptake into forearm muscle, and the greater the fraction (G-L)/O $\mathrm{O}_{2}$. The latter event occurs without demonstrable change in oxygen consumption; that is, glucose appears to be oxidized instead of rather than in addition to something else.

It is to be noted (Table II) that in the two subjects who did not show anxiety and who slept during most of the experiment (G-L)/O $\mathrm{O}_{2}$ was small even during the early hours of observation, five to nine hours after supper. In subject $\mathrm{N}$, who was probably apprehensive, (G-L)/ $\mathrm{O}_{2}$ was higher, and high values were associated with higher concentrations of arterial glucose than were observed in the other subjects during the night and in any of the subjects studied in the basal state.

$R . Q$.

There was no temporal trend in $R$. $Q$. for the group as a whole. Nor was there any correlation between R.Q. and (G-L)/O ${ }_{2}$, perhaps owing to cumulative experimental error. Mean R.Q. for 
the three subjects was 0.82 ; for each subject it was $0.75,0.81$, and 0.89 .

\section{Hematocrit}

There was no real variation in hematocrit during the experiment and there was no difference between hematocrits on paired samples of arterial and venous blood. A decrease in hematocrit with successive blood sampling, particularly noticeable between first and second sample, has been reported by others ( 3 ) but did not occur in this study. It may be noted, however, that there was some blood loss associated with insertion of the arterial needle and venous catheter, so that the sample of blood used for the first hematocrit did not represent the first blood withdrawn from these subjects.

\section{DISCUSSION}

By application of the Fick principle metabolism of resting skeletal muscle (the forearm) has been studied in three normal subjects throughout the night, approximately from 10 P. M. to 11 A. M., a period extending from four to seventeen hours after the last meal.

During this time there were fluctuations in blood flow and in $\mathrm{O}_{2}$ consumption by the forearm, but these followed no definite temporal pattern. In fact, $\mathrm{O}_{2} \mathrm{~A}-\mathrm{V}$ differences were relatively constant and variations in $\mathrm{O}_{2}$ uptake correlated with variations in blood flow in subject $C$. Neither forearm blood flow nor $\mathrm{O}_{2}$ uptake was beyond the range of values obtained in a larger group of subjects examined in the basal state at least 16 hours after the last meal. It might be noted parenthetically that, on the assumption that $\operatorname{limb} \mathrm{O}_{2}$ uptake is constant, changes in $\mathrm{A}-\mathrm{V} \mathrm{O}_{2}$ differences have been used by some as measures of changes in blood flow. The present data show that $\mathrm{O}_{2}$ uptake is not constant and that limb blood flow cannot be estimated in this way. A similar caution has been expressed by Mottram (4) whose findings differ from those reported here in that $\mathrm{O}_{2}$ uptake correlated with $\mathrm{A}-\mathrm{V} \quad \mathrm{O}_{2}$ difference. In subject $\mathrm{K}$ neither flow nor $\mathrm{O}_{2}$ uptake varied sufficiently to permit detection of correlation.

Lactate was produced by the forearm throughout the period of observation but, despite wide variation in its production, there was again no definite temporal pattern. It has been pointed out in our previous report on subjects in the basal state that it is quite remarkable that lactate is produced under resting conditions in the face of vigorous $\mathrm{O}_{2}$ uptake (1). The possibility was considered in that report that there might be areas of intermittent ischemia in the forearm, perhaps as a result of rhythmic vasomotor activity; we have no evidence on this point. It is clear however that lactate production is certainly not a phenomenon of starvation since it occured in the earliest measurements, four hours after a meal.

Furthermore, lactate production accounted for a large fraction of glucose uptake, on the assumption that glucose abstracted from arterial blood was the source of lactate delivered to forearm venous effluent. Since anaerobic glycolysis is less efficient, in terms of energy yield, than aerobic dissimilation of glucose, it is puzzling that the forearm should resort so extensively to lactate production when it obviously has the capacity to oxidize completely all of the glucose it has removed from arterial blood under these conditions. It might be suspected, for example, that lactate production by forearm represents muscle's contribution of carbohydrate to the rest of the body: lactate produced by muscle is delivered to liver, converted to glycogen and released ultimately as glucose. However, if lactate contributed by forearm muscles is typical quantitatively of total body muscle then the total hepatic glucose made available by this means amounts to only about 15 per cent of the glucose released by the liver, a value so small as to make it unlikely that this is an important reason for continuous lactate production by muscle. Even this small contribution represents no net gain for the body as long as muscle lactate arises from dissimilation of glucose. Another possibility is that lactate production may be useful simply because reduced coenzyme, $\mathrm{DPNH}_{2}$, is oxidized during reduction of pyruvate to lactate. However, it is difficult to see that this leads to any gain since the quantity of DPN regenerated in the process is no greater than the quantity reduced during dissimilation of hexose phosphates to pyruvate. There is thus no obvious benefit derived from lactate production by resting muscle.

Glucose uptake, glucose $\mathrm{A}-\mathrm{V}$ difference and arterial glucose concentration all tended to decrease with time. It will be noted in Figure 2 that there is a reasonably linear relation between ar- 
terial glucose concentration and glucose $A-V$ difference, that the $\mathrm{A}-\mathrm{V}$ difference is zero at an arterial glucose concentration of approximately 4.7 $\mathrm{mM}$ per L., and that negative $\mathrm{A}-\mathrm{V}$ differences fall on the straight line which describes the general relation. Two of the negative $\mathrm{A}-\mathrm{V}$ differences differ from zero by twice the standard error of the method. Thus it would appear that negative A-V differences may have been real. Since several large series have been reported in which $\mathrm{A}-\mathrm{V}$ differences in glucose concentration were either always positive or only occasionally negative and this latter not beyond experimental error (5-7) an explanation is needed.

Among several possible explanations for negative $\mathrm{A}-\mathrm{V}$ glucose differences is the possibility that some of the material measured as glucose in venous blood was in fact hexose phosphate derived from skeletal muscle. Although no independent measurement of hexose phosphate was undertaken, data available in the literature (8) suggest that there is far too little hexose phosphate in venous plasma to account for the negative $A-V$ glucose differences which were found.

Since there is no glucose-6-phosphatase in skeletal muscle, any glucose in venous effluent from muscle in excess of that in arterial supply must have diffused into venous blood from the limited mass of preformed glucose in interstitial fluid and perhaps in intracellular water. Diffusion of glucose from interstitial fluid into the blood stream will occur when glucose concentration in arterial blood falls below that in interstitial fluid. This occurs when arterial glucose concentration decreases with time and since there are no large reservoirs of extravascular glucose in muscle, such back diffusion of glucose cannot persist unless arterial glucose concentration falls progressively. When $\mathrm{A}-\mathrm{V}$ glucose differences are plotted against the slope of the arterial glucose concentration it is discovered that negative $\mathrm{A}-\mathrm{V}$ differences occurred at a time when arterial glucose concentration appeared to be falling, suggesting that this is the explanation for observed negative $\mathrm{A}-\mathrm{V}$ differences. However, arterial samples were so infrequent that it is impossible to determine accurately the slope of the arterial glucose-time curve at any point. Since there is some uncertainty, it may be noted that negative $\mathrm{A}-\mathrm{V}$ differences would occur also if the concentration of glucose in interstitial fluid were maintained at a fairly constant value. Thus, net flux of glucose from blood to interstitial fluid occurred when arterial glucose concentration exceeded $4.7 \mathrm{mM}$ per L. of whole blood, or 5.7 $\mathrm{mM}$ per $\mathrm{L}$. of water, and the net flux was reversed when arterial glucose concentration fell below this value.

Somogyi (5) has demonstrated increasing A-V glucose differences as arterial concentration rose following glucose ingestion. The observed fall in $\mathrm{A}-\mathrm{V}$ difference in our subjects in association with a falling arterial glucose concentration then extends these observations and demonstrates the association over a narrow physiological range of arterial concentrations ( 81 to $100 \mathrm{mg}$. per cent). It must be pointed out that these alterations in rate of glucose diffusion from blood in response to small alterations in arterial glucose concentration are violations of the steady-state assumption inherent in application of the Fick principle. In the case of falling arterial concentration, apparent uptake of glucose is falsely low. However, since the changes in arterial concentration were small and probably occurred slowly, it is unlikely that the error was large in these experiments and it is quite improbable that it is large enough to alter the major conclusion that glucose uptake was very small.

Owing to the lack of trend in lactate production and in $\mathrm{O}_{2}$ uptake together with decreasing glucose uptake, the fraction of glucose uptake accounted for by lactate production increased progressively and the fraction of $\mathrm{O}_{2}$ uptake accounted for by glucose oxidation decreased progressively throughout the period of observation. Since decreasing glucose uptake was consequent upon decreasing arterial glucose concentration, the latter event seemed to be responsible for all the relations noted above. The decrease in arterial glucose concentration presumably represents the inability of the liver to maintain steady delivery of glucose as its glycogen stores become exhausted with time. Despite diminished availability of glucose, skeletal muscle appears to continue to produce lactate and consume $\mathrm{O}_{2}$ at a relatively steady rate. Since it is certain that steady $\mathrm{O}_{2}$ consumption in the face of declining glucose uptake implies a shift from glucose to other substrates within muscle, it is conceivable that steady lactate production may imply similarly that the lactate produced by muscle 
may not arise entirely from glucose and that glucose may become a less important source of lactate as fasting progresses. This implies that glycogenolysis is occurring in skeletal muscle at rest. The question of the quantitative role of muscle glycogen as an oxidizable substrate in resting muscle has been treated previously (1), and the conclusion was that its role is minor.

Although it remains unknown what the major fuel for resting skeletal muscle may be, it is clear that oxidation of glucose accounts for only a minor fraction of $\mathrm{O}_{2}$ uptake during most of the period of observation.

\section{SUMMARY}

Certain metabolic events occurring in resting skeletal muscle were studied intermittently over the hours 10 P.M. to 11 A.M., approximately, by measuring appropriate arterio-venous concentration differences and forearm blood flow in three normal men in the post-prandial state. There were patternless fluctuations in blood flow, $\mathrm{O}_{2}$ uptake, $\mathrm{CO}_{2}$ production and lactate production, but the range of values was generally within the variation previously found among a larger group of men who were fasted 16 hours.

Arterial glucose concentration fell progressively and this phenomenon appeared to be responsible in turn for progressive decreases in glucose $\mathrm{A}-\mathrm{V}$ difference, in glucose uptake, in the fraction of $\mathrm{O}_{2}$ uptake estimated to have been spent in oxidation of glucose, and for a progressive increase in the fraction of glucose uptake accounted for by lactate production.

During the entire period oxidation of glucose could account for only a minor fraction of $\mathrm{O}_{2}$ uptake.

\section{ACKNOWLEDGMENT}

We are greatly indebted to Miss Ellen Rogus and Mrs. Gerda von Ahlefeldt for their assistance in the conduct of these studies and in the chemical analyses.

\section{REFERENCES}

1. Andres, R., Cader, G., and Zierler, K. L., The quantitatively minor role of carbohydrate in oxidative metabolism by skeletal muscle in intact man in the basal state. Measurements of oxygen and glucose uptake and carbon dioxide and lactate production in the forearm. J. Clin. Invest., 1956, 35, 671.

2. Andres, R., Zierler, K. L., Anderson, H. M., Stainsby, W. N., Cader, G., Ghrayyib, A. S., and Lilienthal, J. L., Jr., Measurement of blood flow and volume in the forearm of man; with notes on the theory of indicator-dilution and on production of turbulence, hemolysis, and vasodilatation by intra-vascular injection. J. Clin. Invest., 1954, 33, 482.

3. Hanna, C. H., and Marshall, L. H., Effect of sampling on erythrocyte, dye and protein concentrations of venous blood of dogs. Am. J. Physiol., 1955, 182, 331.

4. Mottram, R. F., The relationship between blood flow, arterio-venous oxygen difference, and oxygen uptake of human skeletal muscle. J. Physiol., 1955, 130, $42 \mathrm{P}$.

5. Somogyi, M., Studies of arteriovenous differences in blood sugar. I. Effect of alimentary hyperglycemia on the rate of extrahepatic glucose assimilation. J. Biol. Chem., 1948, 174, 189.

6. Bell, D. M., Femoral arteriovenous sugar differences in fasting human beings. J. Lab. \& Clin. Med., 1952, 40, 337.

7. Elrick, H., Hlad, C. J., Jr., and Witten, T., The enhancement of peripheral glucose utilization by glucagon. J. Clin. Invest., 1955, 34, 1830.

8. Helve, O., On blood phosphorus distribution in certain internal diseases. Acta med. Scandinav., 1946, 125, 505. 